\title{
Effect of varying ambient temperature and solar radiation on the flow in a solar chimney collector
}

\author{
Tahar Tayebi*, Mahfoud Djezzar \\ Energy Physics Laboratory, Department of Physics, Frères Metouri University Constantine, Ä̈n El bey Road, Constantine, 25000 , \\ Algeria
}

\begin{abstract}
The solar chimney is a simple solar thermal power plant that is capable of converting solar energy into thermal energy in the solar collector. The generated thermal energy is converted into kinetic energy in the chimney and ultimately into electric energy using a turbo generator. The aim of the present numerical study is to conduct a more detailed numerical analysis of a collector of the solar chimney. A mathematical model based on the continuity, Navier-Stokes, and energy equations was developed to determine the solar chimney power plant collector mechanism in detail. The basic equations were solved numerically using an iterative method. The distribution of temperature, velocity and pressure in the solar collector are illustrated for the city of "Adrar"-Southern Algeria- to examine the effect of varying ambient temperature and solar radiation on the flow in the collector. A good agreement was obtained between the experimental data of the Manzanares prototype and our results.
\end{abstract}

Keywords: Solar chimney collector, mathematical modeling, southern Algeria

\section{Introduction}

The Solar Chimney Power Plant System is a natural driving power generating system. It can convert solar energy first into thermal energy then into kinetic energy finally into electrical power.

The solar chimney concept was originally proposed by Professor Schlaich of Stuttgart in the late 1970s. Less than 4 years after he presented his ideas at a conference, construction on a pilot plant began in Manzanares, Spain, as a result of a joint venture between the German government and a Spanish utility. A $36 \mathrm{~kW}$ pilot plant was built, which produced electricity for 7 years, thus proving the efficiency and reliability of this novel technology. The chimney tower was $194.6 \mathrm{~m}$ high, and the collector had a radius of $122 \mathrm{~m}$. Due to the complexity of the mechanism involved, most existing publications mainly focused on certain aspects of an SCPP. For example, Haaf et al. [1] which presented a brief discussion of the energy balance, design criteria, and cost analysis. Krisst [2] and Kulunk [3] demonstrated different types of device with a power output not more than $10 \mathrm{~W}$. A mathematical model to study the effect of various environment conditions and geometry on the flow and heat transfer characteristics and output of the solar chimney was developed by Pasumarthi and Sherif [4], [5] and also developed three different models in Florida and reported the experimental data to determine the viability of the solar chimney concept. Bernardes et al. [6] presented a theoretical analysis of a steady state natural laminar convection in a solar chimney, predicting its thermo-hydrodynamic behavior. The approach Finite Volumes Method in Generalized Coordinates was employed allowing a detailed visualization of the effects of geometric of optimal geometric and operational characteristics. Kröger and Buys [7] Presented analytical relations for determining the pressure differential due to frictional effects and heat transfer correlations for developing radial flow between the roof and the collector. Kirstein, et al. [8], Kirstein, and Von Backström [9] presented studies focused on the loss coefficient in the transition section between the turbine and the chimney as dependent on inlet guide vane stagger angle and collector roof height including scaled model

\footnotetext{
* Manuscript received October 11, 2015; revised January 18, 2016.

Corresponding author. Tel.: +21355034949; E-mail address: tahartayebi@gmail.com

doi: $10.12720 /$ sgce.5.1.16-23
} 
experiments and CFD simulations. The good agreement between the simulations and the experiments permits predictions for a proposed full-scale geometry. The solar radiation effect on the flow of the SCPP were presented by Huang, et al. [10]. Approximation of Boussinesq and Discrete Ordinate radiation model were introduced in the model and simulations were carried out. Bernardes and von Backström [11] presented a study on the performance of two schemes of power output control applicable to solar chimney power plants. It was revealed that the optimum ratio is not constant during the whole day and it is dependent of the heat transfer coefficients applied to the collector. Sangi et al. [12] developed detailed theoretical and numerical simulations to simulate the air flow and heat transfer in a solar chimney power plants system.

In Algeria, We are interested in Adrar (southern Algeria) where solar radiation is highly available throughout the year, as well as extensive desert areas. These conditions are favorable for development of a solar chimney power plant. Evaluation of SCPP performances in the region of Adrar has been studied previously. Chergui et al. [13], [14] presented a study, on solar chimney power plants in the south of Algeria. Obtained results showed that the generated power, by this system, depends on the solar radiation, the ambient temperature, the height of the tower and the surface of the collector. The efficiency of the collector and the turbine has a significant role in the improvement of the system performances. Larbi et al. [15] presented the performance analysis of a solar chimney power plant in the southwestern region of Algeria based on the energy balance, and they investigated the effects of various factors on the thermal performance including the solar irradiance, the ambient temperature, the height of the tower, and the surface of the collector.

The aim of the present numerical study is to examine the effects of pertinent parameters such as daily solar radiation and ambient temperature on the distribution of temperature, velocity and pressure in the solar chimney collector using the mathematical model developed by Sangi et al. [12] based on the solution of the governing equations (continuity, Navier-Stokes and energy equations) to describe in detail the variation of temperature, velocity and pressure in the solar chimney power plant. The equations of the model were solved numerically using an iterative method for the geometry of the prototype in Manzanares, Spain.

\section{System Description}

A solar chimney power plant is composed of a solar collector, to raise the energy level of the air by greenhouse effect of a chimney tower ensuring the circulation of air per gradient of density, and of an aero generator to produce electric power (Fig. 1). In its simplest form, the collector is a glass or plastic film cover stretched horizontally and raised above the ground. This covering serves as a trap for reradiation from the ground. A flat collector of this kind can convert a significant amount of the irradiated solar energy into heat. The ground surface under the collector cover is a convenient energy storage medium. During the day, a part of the incoming solar radiation is absorbed by the ground and is later released during the night.

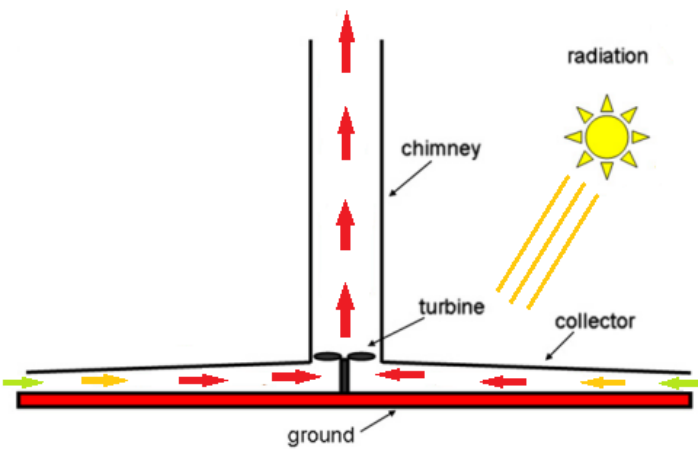

Fig. 1. Schematic drawing of a solar chimney. 


\section{Mathematical Model}

The phenomenon inside the collector of the chimney depends on parameters such as the ambient conditions (insolation, ambient temperature, and wind velocity) and dimensions of the collector. The analysis described in this paper is based on the following simplifying assumptions:

- The collector is placed over a plain surface;

- The flow in the collector is considered as a flow between two parallel plates;

- One-dimensional distribution of flows along the radius of the collector.

The following equation for mass flow rate is obtained:

$$
\dot{q}=u_{f} \rho_{f} S
$$

The velocity of the fluid:

$$
u_{f}=\dot{q} /\left(2 \pi r e \rho_{f}\right)
$$

The energy equation for the warm air in the collector can be expressed as:

$$
\rho_{f} e C_{p} u_{f} \frac{\partial T_{f}}{\partial r}=h_{g}\left(T_{f}-T_{g}(r)\right)+h_{e}\left(T_{f}-T_{e}(r)\right)
$$

For the glass roof, heat balance equation (4) is used. Heat conduction in the very thin cover is neglected compared with heat convection. The heat transfer equation of the glass roof is [12]:

$$
(1-\tau) G=-h_{g}\left(T_{f}-T_{g}\right)-h_{a}\left(T_{a}-T_{g}\right)+\varepsilon_{g} \sigma T_{g}^{4}-\varepsilon_{e} \sigma T_{e}^{4}+\varepsilon_{a} \sigma\left(T_{g}^{4}-T_{a}^{4}\right)
$$

With:

$\tau=0.85[16]$.

$G$ : Is the incident solar energy: beam radiation, diffuse sky radiation, and ground-reflected radiation (the procedure of calculation is described in reference [17]).

$$
T_{\text {sky }}=0.0552\left(T_{a}\right)^{1.5}[15]
$$

The steady-state heat conduction equation is valid in the earth's surface [12]:

$$
\frac{\partial^{2} T_{e}}{\partial z^{2}}=0
$$

Two boundary conditions are required to solve Eq. (5):

$$
\begin{cases}\lambda_{e} \frac{\partial T_{e}}{\partial z}=h_{e}\left(T_{f}-T_{e}\right)+\tau G+\varepsilon_{g} \sigma T_{g}^{4}-\varepsilon_{e} \sigma T_{e}^{4} & ; z=0 \\ T_{e}=T_{a} & ; z=z_{e}\end{cases}
$$

$h_{g}, h_{e}, h_{a}$ : Are the convective heat transfer coefficients between air and collector roof, between air and ground surface and between glass roof and atmosphere, respectively:

$$
\begin{aligned}
& h_{a}=\frac{\lambda}{x} N u_{x} \\
& h_{g}=h_{e}=\frac{\lambda_{f}}{2 \cdot e} N u
\end{aligned}
$$

$N u$ can be gained by Table 1 : 
Tabel 1. Correlations employed for forced and natural convection

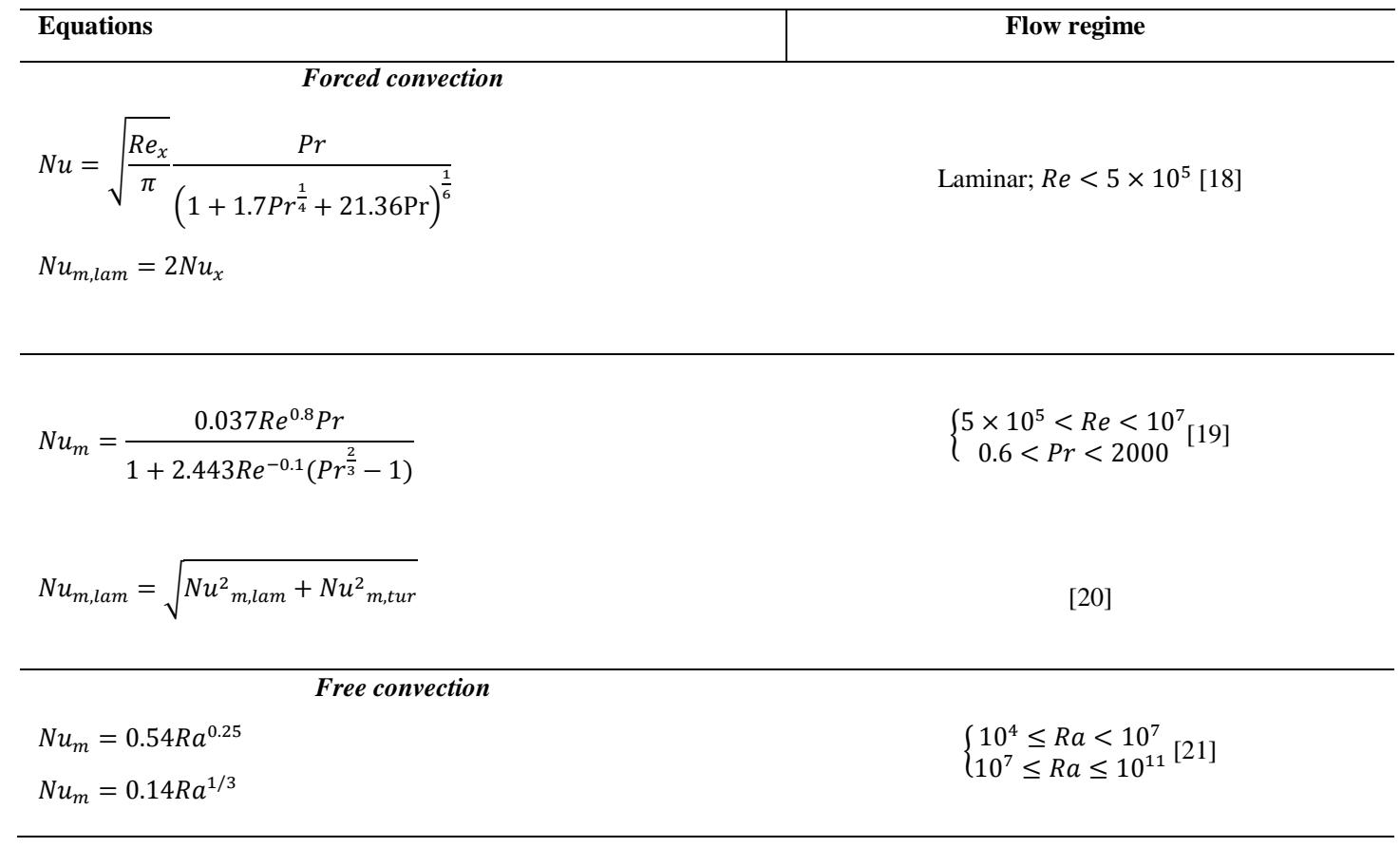

The pressure equation can be derived by simplifying the Navier-Stokes equation. The density model can be expressed by Boussinesq approximation [22]:

$$
\begin{aligned}
& \rho_{f}=\rho_{a}\left(1-\beta_{a}\left(T_{f}-T_{a}\right)\right) \\
& \beta_{a}=\frac{1}{T_{a}}
\end{aligned}
$$

The Navier-Stokes equation in the radial direction is:

$$
u_{f} \rho_{f} \frac{\partial u_{f}}{\partial r}=-\frac{\partial P}{\partial r}
$$

Integrating equation (10) and substituting equation (2) into equation (11) yields [12]:

$$
P(r)=\frac{\dot{q} \rho_{a}\left(\frac{1}{r_{0}^{2}}-\frac{1}{r^{2}}\right)}{8 e^{2} \pi^{2} \rho_{f}^{2}}
$$

The physical properties of air are calculated by interpolation of data from standard tables [23].

\section{Results and Discussion}

The numerical solution of the model was obtained for the geometry of the prototype in Manzanares, Spain [24]. The model solved iteratively, an algorithm based on iteration is proposed. We illustrate the temperature, velocity and pressure distributions in the collector of the solar chimney power plant for the month of June (we choose the day of June 15th as a day of computing) and for three different times of day $\left(07: 00,13: 00\right.$ and 18:00) from the city of Adrar, which located in the south western region of Algeria, $\left(27^{\circ}\right.$ $53^{\prime} \mathrm{N}, 0^{\circ} 17^{\prime} \mathrm{W}$ ) where the solar layer is appreciable.

Fig. 2(a) gives the theoretical daily variations of the solar radiation and the ambient temperature of 
Adrar site. We can note that the maximum daily ambient temperature, which reaches the $316.15 \mathrm{~K}$, occurs at 14:00. The variation of the solar radiation is different from that of the ambient temperature; the maximum of radiation is at 13:00 with a value of $956.46 \mathrm{~W} / \mathrm{m}^{2}$. We also note that the decrease in solar radiation is rapidly after 13:00 on the contrary the ambient temperature at which the decreasing less after 14:00.
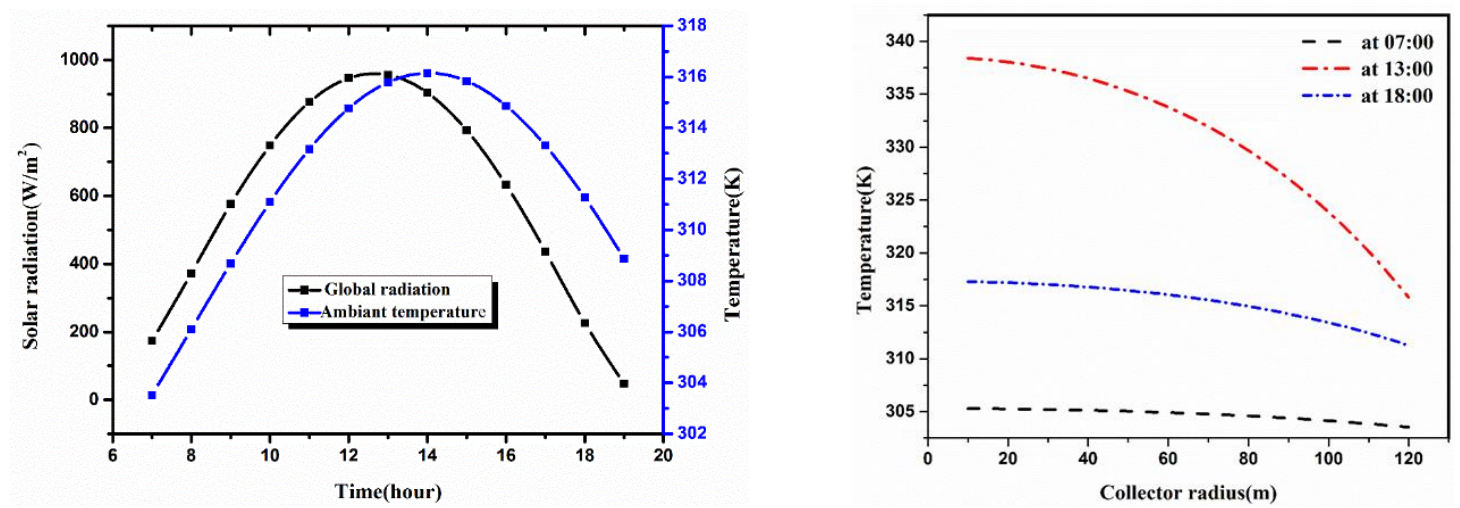

Fig. 2. (a): solar radiation during the day for normal conditions; (b): temperature profile of the fluidflowing through the collector.

Fig. 2(b) shows the influence of solar radiation and collector radius on the temperature profile of fluid flowing through the collector. When the time is constant (solar radiation is constant), the temperature of fluid increases by decreasing the radius. When the solar radiation increases (the maximum is at 13:00), the air temperature increases for the same collector radius.

Fig. 3(a) presents the theoretical hourly variation of the temperatures difference between the ambiance and chimney base on the 15th day of June. We note that the difference increases with increasing solar radiation even up to a maximum extent $22 \mathrm{~K}$, Where the solar radiation at the maximum level at 13:00.
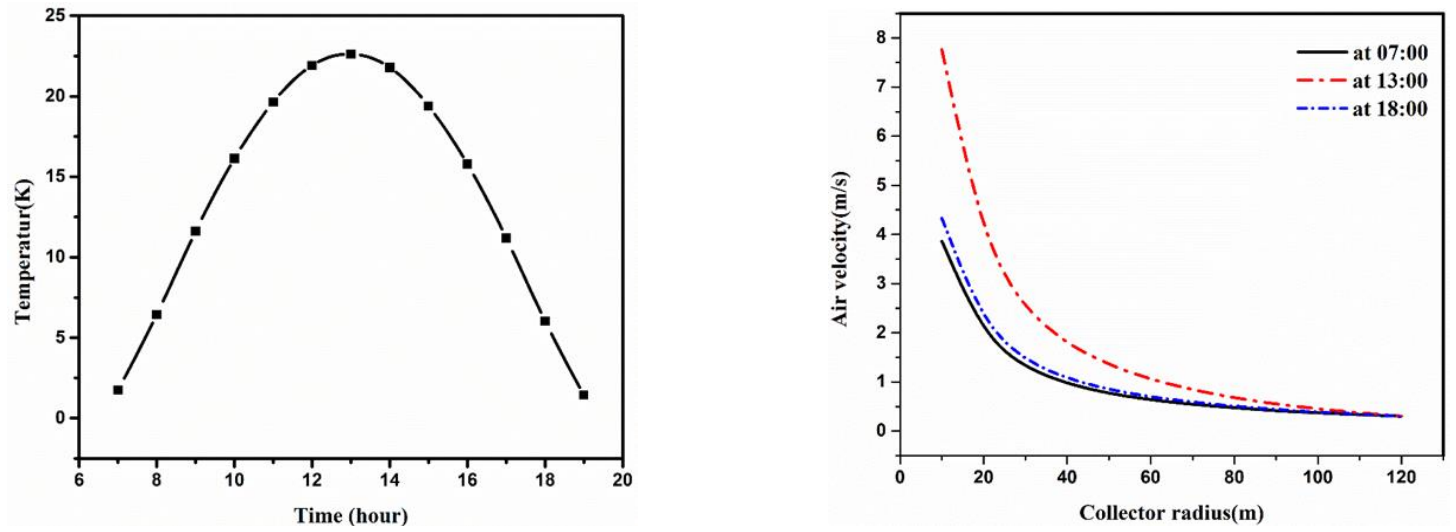

Fig. 3. (a) temperature difference between the ambiance and chimney base during the day, (b) velocity profile of the fluid flowing through the collector.

Fig. 3(b) shows the air velocity profile through the collector for both the model. The velocity increases through the collector by decreasing the radius, but it increases more sharply by reaching the chimney base. When the collector radius is constant, an increase of solar radiation causes an increase of the air velocity.

Fig. 4 shows the static pressure profile, which decreases through the collector and drops dramatically near the chimney base. It also demonstrates that increasing solar radiation results in a decrease in the static pressure when the collector radius is constant. 


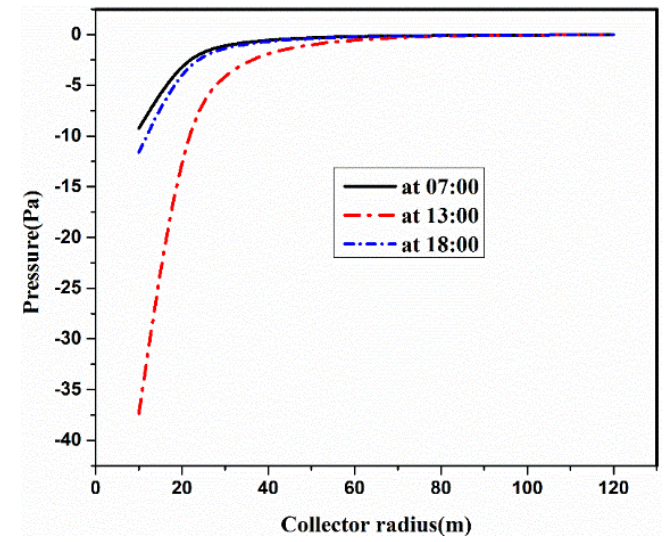

Fig. 4. Static pressure profile of the fluidflowing through the collector.

\section{Validation of the Numerical Results}

To validate the numerical results, the temperature increase in the collector was compared with the experimental data of the Spanish prototype for $1000 \mathrm{~W} / \mathrm{m}^{2}$ [1] As is shown in Table 2, good quantitative agreement was obtained between the experimental data of the Manzanares prototype and both of the numerical results.

Table 2. Comparison between the numerical results and the experimental data

\begin{tabular}{l|c}
\hline Results & Temperatureincrease \\
\hline Experimental data from Manzanares & $20 \mathrm{~K}$ \\
Our work & $20.35 \mathrm{~K}$ \\
Divergence & $1.75 \%$ \\
\hline
\end{tabular}

\section{Conclusion}

The objective of this study was to evaluate the collector of solar chimney performance theoretically. A mathematical model was developed to accurately describe the solar chimney power plant mechanism. A numerical solution was performed to estimate the profiles for the temperature, velocity and pressure in the collector of the solar chimney power plant for the geometry of the prototype in Manzanares, Spain, for different solar radiations (different daily time) in the city of Adrar (Algeria).The mathematical model was validated with the experimental data from the prototype in Manzanares. The results demonstrate that, the temperature and velocity of fluid increases by decreasing the collector radius (but the velocity increases more sharply by reaching the chimney base). The static pressure profile decreases through the collector and drops considerably near the chimney base.

This change in these quantities we can produce more than 200KWh of electricity [25], on a site like that of Adrar, and that lasts all the year, according to an estimate made on the monthly average of sunning. This production is sufficient to satisfy the needs of the isolated areas, and the solar heat collector of the device could be also used as a greenhouse for agricultural uses.

\section{Nomenclature}

$\mathrm{C}_{\mathrm{p}} \quad$ Specific heat capacity, $\mathrm{J} \cdot \mathrm{kg}^{-1} \cdot \mathrm{K}^{-1}$

d Diameter, $m$

$e \quad$ Height of the cover, $m$

g Gravitational acceleration, $\mathrm{m} / \mathrm{s}^{2}$

$G$ Global solar radiation, $\mathrm{W} / \mathrm{m}^{2}$ 


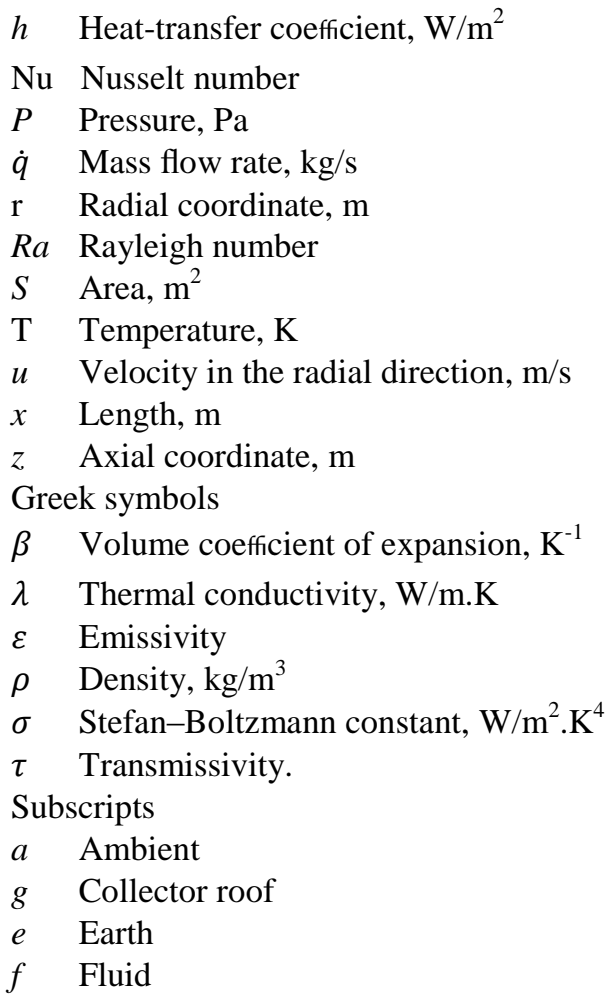

\section{References}

[1] Haaf W, Friedrich K, Mayr G, Schlaich J. Solar chimneys: parti: principle and construction of the pilot plant in Manzanares. International Journal of Solar Energy, 1983; 2:3-20.

[2] Krisst RJK. Energy transfer system. Alternative Source Energy, 1983; 63:8-11.

[3] Kulunk H. A prototype solar convection chimney operated under Izmit conditions. In: Proc. of the 7th Miami International Conference on Alternative Energy Sources, Veiroglu, TN; 1985:162.

[4] Pasumarthi N, Sherif SA. Experimental and theoretical performance of a demonstration solar chimney model-Part I: mathematical model development International. J. Energy Res., 1998; 22:277-88.

[5] Pasumarthi N, Sherif SA. Experimental and theoretical performance of a demonstration solar chimney model-Part II: experimental and theoretical results and economic analysis. Int. J. Energy Res., 1998; 22:443-61.

[6] Bernardes MADS, Valle RM, Cortez MF-B. Numerical analysis of natural laminar convection in a radial solar heater. Int. J. Therm Sci., 1999; 38:42-50.

[7] Kröger, DG, Buys JD. Radial Flow Boundary Layer Development Analysis, South African Inst. of Mechanical Eng. R \& D J., $1999 ; 15: 95-102$

[8] Kirstein CF, Backström TWV. Flow through a solar chimney power plant collector-to-chimney transition section. Journal of Solar Energy Engineering, Transactions of the ASME, 2006; 128:312-317.

[9] Kirstein CF, et al. Flow through a solar chimney power plant collector-to-chimney transition section. presented at: International Solar Energy Conference, Orlando, FL; 2005.

[10] Huang H, et al. Simulation calculation on solar chimney power plant system. In Challenges of Power Engineering and Environment, 2007:1158-1161.

[11] Bernardes MADS, et al. Analysis of some available heat transfer coefficients applicable to solar chimney power plant collectors. Solar Energy, 2009; 83:264-275.

[12] Sangi R, Amidpour M, Hosseinizadeh B. Modeling and numerical simulation of solar chimney power plants. Solar Energy, 2011; 85:829-38.

[13] Chergui T, Larbi S, Bouhdjar A, Gahgah M. Performances analysis of a solar chimney power plant in South of Algeria. In: Proc. of the World Renewable Energy Congress, 2008.

[14] Chergui T, Larbi S, Bouhdjar A. Modelling and simulation of solar chimney power plant performances in southern region of 
Algeria. presented at the Modeling, 4th International Conference on Simulation and Applied Optimization, 2011.

[15] Larbi S, Bouhdjar A, Chergui T. Performance analysis of a solar chimney power plant in the southwestern region of Algeria. Renewable and Sustainable Energy Reviews, 2010; 14:470-477.

[16] Grigull U, Siegel S, Howell JR, Lohrengel J. Warmeubertragung Durch Strahlung Teil2 Strahlungsaustausch Zwischen Oberflachen und in Umhu“llungen. Springer Verlag; 1991.

[17] Tayebi T, Djezzar M. Notions de Gisement Solaire: Théorie et Exercices. Éditions Universitaires Européennes; 2014.

[18] Baehr HD, Stephan K. Warme-Und StoffÜbertragung. Berlin: Springer-Verlag; 1996.

[19] Petukhov BS, Popov NV. Theoretical calculation of heat transfer and frictional resistance in turbulent flow in tubes of an incompressible fluid with variable physical properties. High Temperature, 1963; 1:69-83.

[20] Schlichting H, Gersten K, Krause E, Mayes K, Oertel H. Boundary-Layer Theory. Berlin: Springer-Verlag; 1999.

[21] Churchill SW, Chu HHS. Correlating equations for laminar and turbulent free convection from a vertical plate. Int. J. Heat Mass Transfer, 1975; 18:1323-1329.

[22] Jaluria J. Natural Convection Heat and Mass Transfer. Oxford: Pergamon Press; 1980.

[23] Warmeatlas. VDI - Warmeatlas. Berlin: Springer-Verlag; 1997.

[24] Schlaich J. The Solar Chimney Edition Axel Menges. Stuttgart, Germany; 1995.

[25] Schiel W. Experimental data from the solar chimney prototype in Manzanares (Spain). Private Communications with the Buro Schlaich Bergermann und Partner, 2002. 